\title{
Atmospheric response to sea surface temperature mesoscale structures
}

\author{
J. Lambaerts, ${ }^{1,2}$ G. Lapeyre, ${ }^{1}$ R. Plougonven, ${ }^{1}$ and P. Klein ${ }^{3}$ \\ Received 28 January 2013; revised 12 August 2013; accepted 16 August 2013; published 6 September 2013.
}

[1] Recent studies have revealed that strong sea surface temperature (SST) fronts, on the scale of a Western Boundary Current, significantly affect not just the Marine Boundary Layer but the entire troposphere. This has aroused renewed interest in air-sea interactions. The present study investigates the atmospheric response to fixed SST anomalies associated with mesoscale oceanic eddies and submesoscale filaments, using idealized simulations. Our main result is that in weak wind conditions, the vertical velocity in the planetary boundary layer (PBL) is linearly proportional to the SST Laplacian. This is established by a quantitative analysis in the spatial space as well as in the spectral space. Comparing the responses to two different SST fields shows that vertical velocities are much more intense when the submesoscales are more energetic. These results hold for different configurations of the atmospheric large-scale state and for different PBL parameterizations. Surface winds play the role of low-pass filter and reduce the response at the smaller scales. To our knowledge, this study is the first to clearly reveal the high impact of oceanic submesoscales on the atmospheric boundary layer at midlatitudes, as well as the direct link between the vertical velocity and the SST Laplacian.

Citation: Lambaerts, J., G. Lapeyre, R. Plougonven, and P. Klein (2013), Atmospheric response to sea surface temperature mesoscale structures, J. Geophys. Res. Atmos., 118, 9611-9621, doi:10.1002/jgrd.50769.

\section{Introduction}

[2] Air-sea interactions near midlatitude surface sea temperature (SST) fronts have aroused renewed interest in recent years. High-resolution simulations and satellite observations have shown how SST fronts associated to western boundary currents (of the order of $300 \mathrm{~km}$ of width) have a clear impact throughout the whole troposphere, not just within the Marine Atmospheric Boundary Layer (MABL) [Minobe et al., 2008; Nakamura et al., 2008; Deremble et al., 2012]. The SST fronts not only affect the position of the upper tropospheric jet [Nakamura et al., 2004; Deremble et al., 2012] but also its low-frequency variability such as the North Atlantic Oscillation [Feliks et al., 2004, 2007]. All these mechanisms are totally missed when using a climatological SST (such as the Reynolds SSTs) because the time filtering smooths the strong gradients as well.

[3] Satellite observations have allowed systematic investigation of the relations between SST anomalies at scales of $300 \mathrm{~km}$ and less and near-surface winds, and in particular,

\footnotetext{
${ }^{1}$ Laboratoire de Météorologie Dynamique/IPSL, Ecole Normale Supérieure/CNRS/UPMC/Ecole Polytechnique, Paris, France.

${ }^{2}$ Center for Atmosphere Ocean Science, Courant Institute of Mathematical Sciences, New York, New York, USA.

${ }^{3}$ Laboratoire de Physique des Océans, UMR 6523, CNRS/IFREMER/ UBO/IRD, Plouzané, France.

Corresponding author: R. Plougonven, Laboratoire de Météorologie Dynamique/IPSL, Ecole Polytechnique, 91128 Palaiseau, France. (riwal.plougonven@polytechnique.org)

(C)2013. American Geophysical Union. All Rights Reserved. 2169-897X/13/10.1002/jgrd.50769
}

their divergence and convergence. The review of Small et al. [2008] and the observational and numerical studies of Businger and Shaw [1984], Bourras et al. [2004], and Shuckburgh et al. [2011] indicate that the MABL can respond to mesoscale anomalies such as oceanic eddies of scales of $100 \mathrm{~km}$ of diameter and to oceanic fronts [Doyle and Warner, 1990; Giordani and Planton, 2000]. Recent observations involving ocean fronts with 10-100 km scale also support the relationship of these fronts with wind divergence patterns: analysis of tracking of frigate birds indicate a co-occurrence with small-scale ocean fronts that appears to be a consequence of upward vertical winds [De Monte et al., 2013]. Several mechanisms have been proposed to capture and explain the main features of air-sea interactions near mesoscale SST fronts.

[4] A first mechanism is based on the destabilization of the atmospheric layers above the SST anomalies that induces a stronger (weaker) surface wind above warmer (colder) water [Wallace et al., 1989]. It is referred as the downward momentum mixing mechanism [O'Neill et al., 2003; Chelton et al., 2004]. This mechanism can be expressed as a linear correspondence between the divergence of the wind stress perturbation $\nabla \cdot \boldsymbol{\tau}$ and the (high-pass-filtered) downwind SST gradient field $\hat{\boldsymbol{\tau}} \cdot \nabla S S T$, where $\hat{\boldsymbol{\tau}}$ is the unit vector in the direction of the wind stress.

[5] Another mechanism has been suggested by Lindzen and Nigam [1987], hereafter LN87, in the context of tropical dynamics and larger scales. It relates the divergence of the wind in the boundary layer to the Laplacian of the SST field. In their study, Lindzen and Nigam [1987] consider an approximately steady flow and a weak wind regime 
allowing to neglect the advection terms so that the equation of momentum in the boundary layer becomes

$$
f \hat{z} \times \boldsymbol{V}=-\nabla \Phi-\epsilon \boldsymbol{V},
$$

where $\boldsymbol{V}$ and $\Phi$ are the weight averaged velocity and pressure in the boundary layer and $\epsilon$ the normalized drag coefficient using a simple linear drag. The authors also express the pressure gradient in terms of the SST perturbation by using the hydrostatic equation and assuming that the mean temperature in the boundary layer adjusts to the SST: $\nabla \Phi \simeq \kappa \nabla \mathrm{SST}$ with $\kappa=R \log \left(P_{0} / P_{h}\right), P_{0}=1011 \mathrm{hPa}$ and $P_{h}$ the pressure at the top of the planetary boundary layer (PBL). Doing so (and neglecting the $\beta$ effect), the momentum balance leads to a linear relation between the wind divergence and the SST Laplacian:

$$
\nabla \cdot \boldsymbol{V}=\frac{\kappa \epsilon}{f^{2}+\epsilon^{2}} \nabla^{2} \mathrm{SST}
$$

Although not explicitly discussed by Lindzen and Nigam [1987], a linear relation between the vertical velocity $w$ and the SST Laplacian is straightforwardly obtained by integrating this equation from the surface:

$$
w(z)=-\frac{\kappa \epsilon z}{f^{2}+\epsilon^{2}} \nabla^{2} \mathrm{SST} .
$$

[6] This mechanism, also referred as the pressure adjustment mechanism [Lindzen and Nigam, 1987; Wai and Stage, 1989], has since been used in a context different than that for which it was derived. Its relevance was assumed for synoptic scales at midlatitudes, in particular, to explain the strong convection region appearing above the warm side of the SST front of the Gulf Stream [Minobe et al., 2008; Takamata et al., 2012]. It has also been revisited by Feliks et al. [2004] who used it as a parameterization to study the low-frequency variability induced by an oceanic thermal front in an idealized atmospheric model in the midlatitudes.

[7] In practice, the SST field comprises intense anomalies at the mesoscales (horizontal scales of the order of $300 \mathrm{~km}$ ) and submesoscales (scales of the order of $10 \mathrm{~km}$ ). The distinctive feature of the LN87 mechanism is that it suggests a stronger impact of the SST submesoscales via the Laplacian operator, whereas the downward momentum mixing mechanism is less sensitive to these scales (involving the SST gradient only). These submesoscales can be highly energetic at midlatitudes as it has been shown by Klein et al. [2008] in their high-resolution oceanic simulations.

[8] In the present study, we address the role of the SST submesoscales in the atmospheric boundary layer dynamics. This investigation is a first step, exploring the atmospheric response under weak wind conditions. The aim of this paper is to highlight the LN87 mechanism and the importance of its impact in this context; for stronger winds, mechanisms may differ, but this competition is beyond the scope of the present study. Numerical simulations are performed with an idealized atmospheric model under adequate conditions of weak wind regime (described in section 2). A unidimensional case is discussed in section 3 to illustrate the response of the atmospheric vertical velocity to the SST Laplacian and not to the SST anomalies themselves. Then, the atmospheric responses of two different 2-D SST patterns are analyzed (sections 4 and 5), one pattern (section 5) involving more energetic submesoscale features than the other. In both cases, the linear relation provided by this mechanism is accurately reproduced, even in midlatitudes. The comparison between the two cases reveals a more intense vertical kinetic energy associated with the submesoscales. Finally, in section 6 , tests on the sensitivity of the boundary layer response to different factors, such as the intensity of the surface wind and its vertical shear, are described. Section 7 is dedicated to a discussion of the present results.

\section{Model configuration}

[9] We use an idealized configuration of the Weather Research Forecast Model (WRF) for a dry atmosphere on the $f$ plane. The atmospheric dynamics is solved by integrating the compressible, nonhydrostatic Euler equations [Skamarock et al., 2008]. In these simulations, we choose the top height fixed at $H_{\text {top }}=12 \mathrm{~km}$ representing the tropopause. The horizontal domain corresponds to a square domain of length $L=512 \mathrm{~km}$, at a latitude such that $f=10^{-4} \mathrm{~s}^{-1}$. Periodic conditions in the zonal direction and free slip conditions on the meridional walls are chosen which are consistent with an eastward atmospheric jet above a meridional sea surface temperature (SST) gradient. This atmospheric jet in thermal wind balance consists in a linear vertical shear

$$
U(z)=U_{H} \frac{z}{H_{\text {top }}}
$$

where $U_{H}=10 \mathrm{~ms}^{-1}$ corresponding to a Rossby number value of 0.1 for the synoptic length scale $(1000 \mathrm{~km})$, with a uniform background stratification such that $N=10^{-2} \mathrm{~s}^{-1}$. This jet is prepared and numerically adjusted following Plougonven and Zeitlin [2009]. A state of rest is not desirable (too idealized) and impractical (PBL parameterizations are not designed for such a case).

[10] The simulations will be performed with fixed SST anomalies, the SST field being decomposed in three parts: a linear background meridional gradient equal to the atmospheric temperature gradient (obtained through thermal wind balance), an homogeneous positive anomaly of $3 \mathrm{~K}$ and a prescribed perturbation field $f(x, y)$ (which will be defined below). Since the homogeneous positive anomaly of $3 \mathrm{~K}$ guarantees a higher SST than the surface atmospheric temperature in all the domain, it initially causes positive sensible heat fluxes over all the domain, which gradually lead to the emergence of an atmospheric boundary layer of realistic height. Note also that this is typically the case for midlatitude winter along the western boundary currents with cold air from the continent coming over a warmer ocean. We primarily focus our attention on the time evolution of this atmospheric response during the first day, so that it is justified to use a stationary SST.

[11] The influence of the SST field on the atmosphere is provided by the surface layer turbulence and the planetary boundary layer (PBL) schemes. In the reference simulation, a standard Monin-Obukhov similarity theory surface layer scheme is run in conjunction with the Yonsei University (YSU) PBL scheme [Hong et al., 2006].

[12] The numerical resolution that will be used in the following is $2 \mathrm{~km}$ in the horizontal and 80 vertical levels (with 12 vertical levels below $1000 \mathrm{~m}$ ). A simulation with equally spaced vertical levels near the surface does not lead to differences in the results (not shown). To avoid small-scale 
(a)

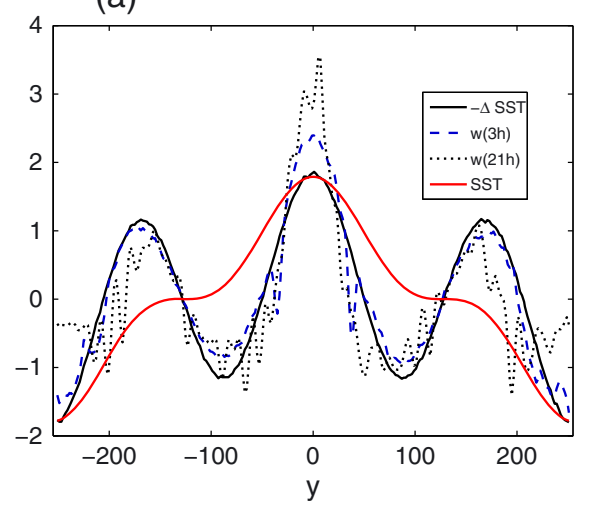

(b)

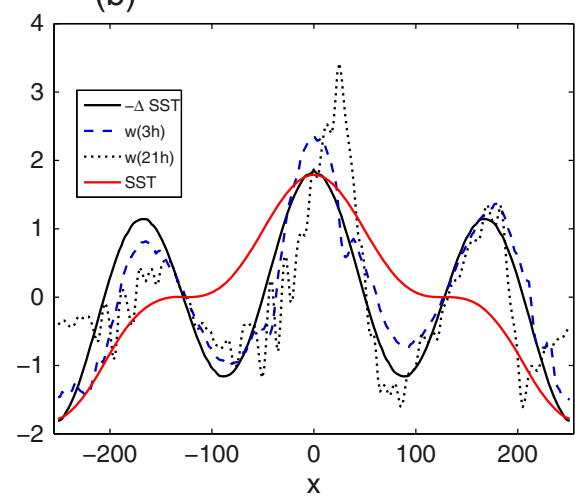

Figure 1. Normalized Laplacian of SST field at the center of the meridional domain (plain line) and the associated normalized response in vertical velocity $w$ at the center of the mean MABL height at $t=3 \mathrm{~h}$ (dashed line) and $t=21 \mathrm{~h}$ (dotted line) for the two-modes SST perturbation (red line) in the (a) cross-jet direction $y$ and (b) jet direction $x$ (in $\mathrm{km}$ ). All the curves are normalized by their original root-mean-square deviation.

numerical instabilities, a sixth-order spatial filter is applied on horizontal coordinates [Knievel et al., 2007].

\section{Illustrative Unidimensional Case}

[13] We first present a test with the following simple SST perturbation, varying only in the direction transverse to the basic wind ( $f$ in Kelvin units),

$$
f(y)=0.75 \cos \left(\frac{2 \pi}{L} y\right)+0.25 \cos \left(3 \frac{2 \pi}{L} y\right)
$$

It includes the first and the third modes of the meridional domain. Whereas the first mode dominates in the SST field, the third mode dominates the SST Laplacian (see Figure 1a). This allows to easily distinguish the nature of the response in the vertical velocity field $w$. We present in Figure 1a the meridional profile of the vertical velocity $w$ at the midheight $(h / 2)$ of the PBL, at $3 \mathrm{~h}(h / 2=345 \mathrm{~m})$ and $21 \mathrm{~h}$ $(h / 2=433 \mathrm{~m})$. The vertical velocity has been normalized in order to be compared with $-\nabla^{2} \mathrm{SST}$ (amplitudes are not discussed in this section). When adequately normalized, the vertical velocity at $3 \mathrm{~h}$ and $21 \mathrm{~h}$ strikingly exhibits the same mode 3 as the SST Laplacian and the patterns of $w$ and $-\nabla^{2}$ SST match quite well with each other. A difference occurs near the center of the domain in the region where the SST anomaly is positive. This is not the case for the two other peaks at $y= \pm 175 \mathrm{~km}$ for which the SST anomaly is weaker. One explanation could be that the convergence of surface winds induced by the SST gradients is reinforced by the localized heating (enhancing dry convection) above the maximum of SST anomaly. Comparing $w$ at $3 \mathrm{~h}$ and $21 \mathrm{~h}$, the pattern does not change much except for the central peak and for small-scale perturbations that gradually develop over time and result at least in part from the activity of gravity waves generated by dry convection (not shown).

[14] In the above, the SST perturbation is set in the crossjet direction $y$ and the advection produced by the background jet has no effect. The experiment was repeated but with the SST perturbation varying in the jet direction $x$. Results are shown in Figure 1b. At $t=3 \mathrm{~h}$, the $w$ profile is also very similar to the Laplacian of the SST. This suggests that, at least for values chosen here, this result is not dependent on the crosswind or downwind direction of the wind relatively to the SST fronts, as would be the case in the schematic argument of Chelton et al. [2004]. At $t=21 \mathrm{~h}$, we observe a zonal shift of the vertical velocity to the east of the Laplacian SST profile that can be attributed to the advection of atmospheric temperature by the atmospheric shear. Assuming, as can be obtained from LN87, that the vertical velocity is tied to the temperature in the PBL, a zonal shift of temperature (compared to the SST) will result in a zonal shift of the vertical velocity.

[15] These two simple experiments give first indications of the direct relation between vertical velocities and SST Laplacian and form a starting point for our study. The next sections are dedicated to the impact of a highly inhomogeneous SST field on the PBL.

\section{Response to a Bidimensional SST Pattern}

[16] We now consider the more general case of a SST field associated with a turbulent mesoscale oceanic eddy field.

[17] Figure 2a shows the spatial patterns of the SST perturbation $f(x, y)$. It has been constructed by using as a substitute the vorticity field of a 2-D barotropic turbulent simulation in free decay. Its isotropic wavenumber spectrum $E(k)$ with a $k^{-4}$ power law (see Figure 5 which shows the SST Laplacian spectrum) is steeper than the $k^{-2}$ law expected in the real ocean [Klein et al., 2008]. However, the SST anomalies displayed on Figure 2a still exhibit coherent spatial structures close to those observed in the ocean, such as vortices of $50-100 \mathrm{~km}$ diameter. Figure $2 \mathrm{~b}$ shows the complete SST spatial pattern that also includes a large-scale meridional gradient such that it resembles a typical region of the North Atlantic.

[18] Despite the steep SST spectrum and the absence of submesoscale $(10 \mathrm{~km})$ anomalies (filaments) in the SST field, the Laplacian of the SST field exhibits both mesoscale $(100 \mathrm{~km})$ and submesoscale structures (Figure 2c). This case is therefore a good candidate to test the link deduced following LN87 between the vertical velocity and the SST 
(a)

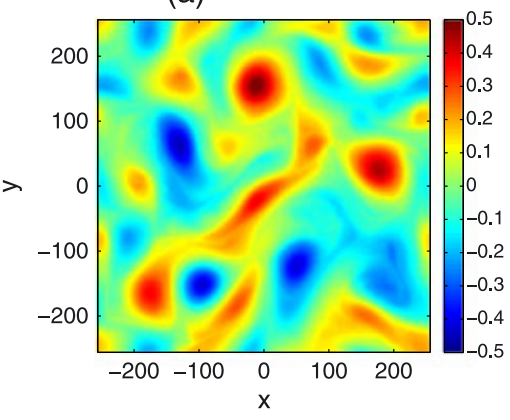

(d)

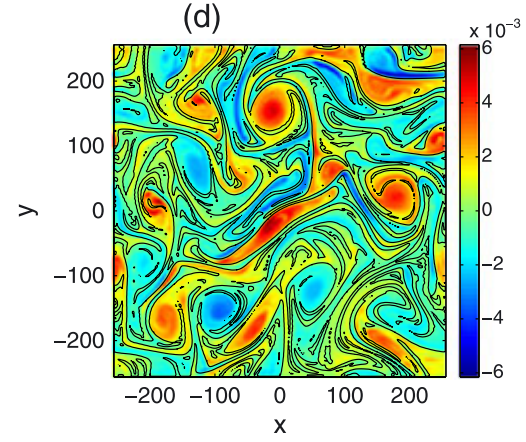

(b)

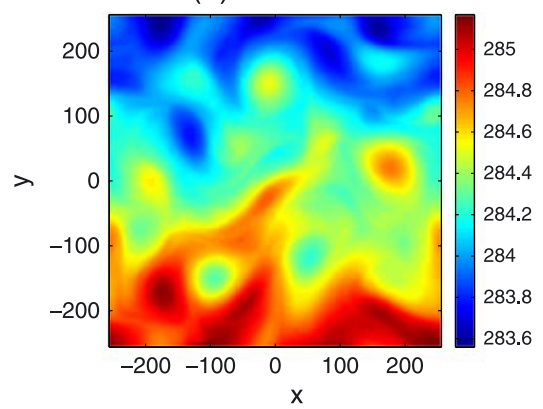

(e)

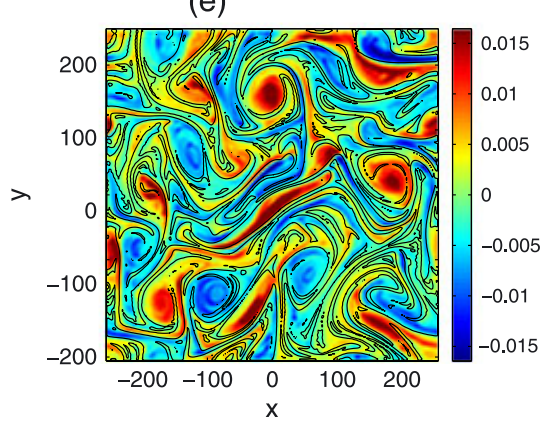

(c)

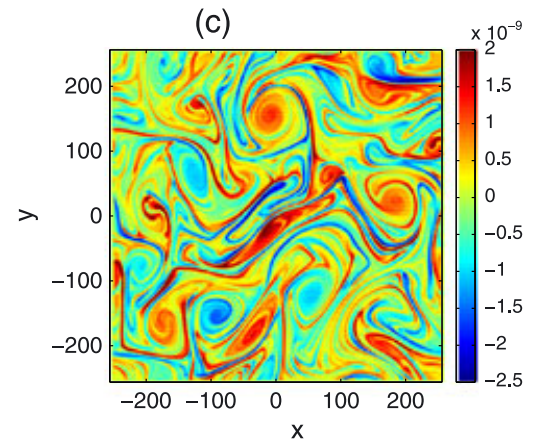

(f)

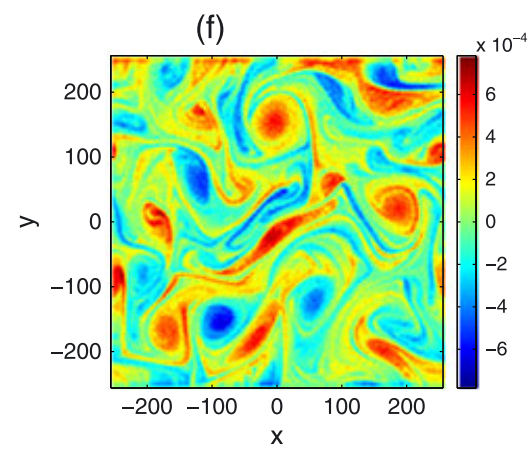

Figure 2. (a) SST perturbation field $f(x, y)$ of the reference case. (b) Total SST pattern (in K). (c) Minus the Laplacian of the SST field (in $\mathrm{K} \mathrm{m}^{-2}$ ). Vertical velocity field $w$ (in $\mathrm{m} \mathrm{s}^{-1}$ ) at the center of the mean PBL height at (d) $t=3 \mathrm{~h}$ and (e) $t=15 \mathrm{~h}$. (f) Same as Figure $2 \mathrm{~d}$ but for the local Mellor-Yamada-NakanishiNiino (MYNN) PBL scheme. SST Laplacian in black contours, axes $x$ and $y$ in Kilometers.

Laplacian. This simulation will serve as the reference simulation in the following.

[19] The atmospheric dynamical response to the SST pattern is relatively rapid, it occurs in a few hours. The emerging boundary layer reaches $400 \mathrm{~m}$ in $1 \mathrm{~h}$ and goes up to $1000 \mathrm{~m}$ after $25 \mathrm{~h}$ (see Figure 4). Vertical kinetic energy keeps growing as a function of time but stays confined in the PBL (not shown).

[20] Figure 2d shows the $w$ field at the mid-height of the PBL $(z=345 \mathrm{~m})$ at $t=3 \mathrm{~h}$. The signature of the Laplacian of the SST field is all the more evident when comparing this latter with Figure 2c. The correspondence not only occurs at mesoscales but also at submesoscales. On the contrary, comparing Figure $2 d$ with Figure $2 b$, the SST pattern bears almost no resemblance at submesoscale with the vertical velocity pattern. This experiment indicates that the strong relationship between vertical motions and SST Laplacian is consistent with LN87 or Feliks et al. [2004]. Further evidence is provided when analyzing the surface relative vorticity and divergence fields: these fields display the same similarity with the SST Laplacian (not shown). Typical values of these two fields at time $t=3 \mathrm{~h}$ are about $3 \times 10^{-6} \mathrm{~s}^{-1}$ for surface vorticity and $10^{-5} \mathrm{~s}^{-1}$ for surface divergence. To our knowledge, this provides the first evidence that, at least for short time scales and weak surface winds, the atmospheric boundary layer is responding to the SST Laplacian both at mesoscales and submesoscales in midlatitudes.

[21] At $t=15 \mathrm{~h}$, one observes that the vertical velocities are shifted eastward and are intensified on the downwind boundary of positive SST anomalies (see for instance at $x=0 \mathrm{~km}$ and $y=150 \mathrm{~km}$ in Figure 2e), in agreement with what we observed in the 1-D simulations. But, over all, the correspondence between $w$ and the SST Laplacian is still striking. Negative anomalies in vertical velocity seem to be less advected and are of smaller amplitude than the positive ones. We suspect that there is a nonlinear response that enhances upward vertical velocities on the downwind side of SST gradients in regions of positive SST anomalies.

[22] Inspecting more closely Figure $2 \mathrm{~d}$, we see that local extrema in positive vertical velocities are always of larger amplitude than negative ones for the same amplitude of the SST Laplacian. A more detailed analysis can be performed using Figure 3 which shows the probability density function

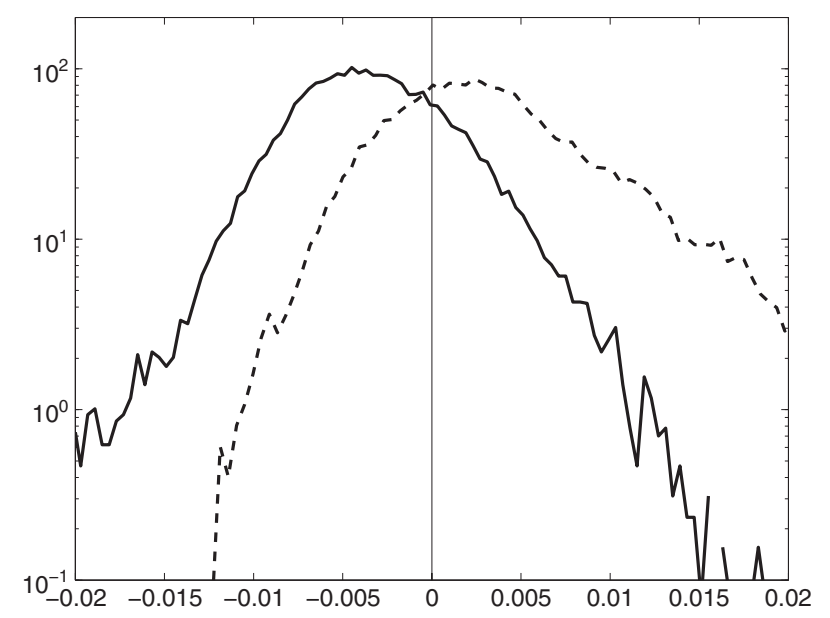

Figure 3. Probability density function of vertical velocities in regions where $\nabla^{2} \mathrm{SST}>0$ (continuous curve) and $\nabla^{2} \mathrm{SST}<0$ (dashed curve) at $t=15 \mathrm{~h}$. 
(a)

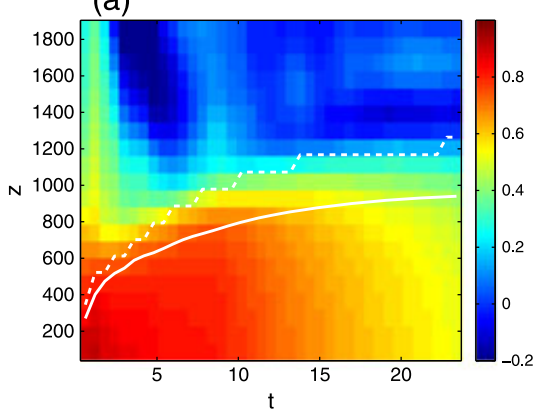

(c)

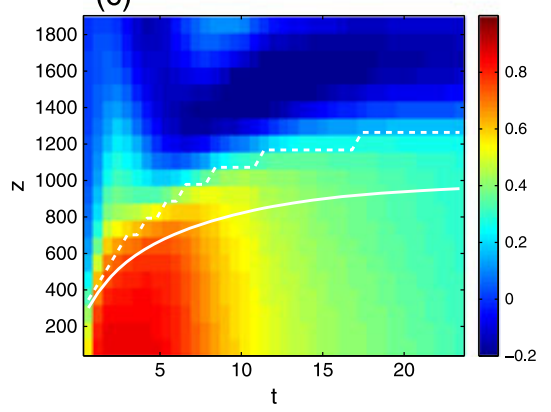

(b)

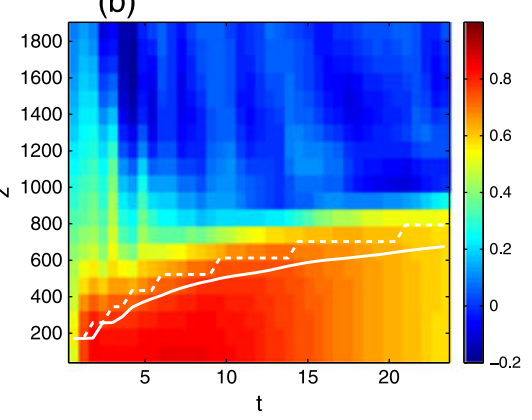

(d)

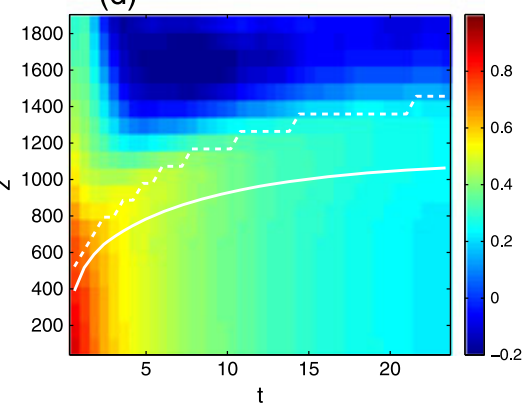

Figure 4. Spatial correlation index between $w$ et $-\nabla^{2} \mathrm{SST}$, as function of time (in h) and altitude (in $\mathrm{m}$ ) for (a) the reference case, (b) the local MYNN PBL scheme, (c) for a doubled vertical shear $\left(U_{H}=20 \mathrm{~ms}^{-1}\right)$, (d) with an additional uniform wind $\left(U_{0}=1 \mathrm{~ms}^{-1}\right)$. The maximum and the mean PBL heights are denoted by the dashed and plain white lines, respectively.

(pdf) of $w$ for regions where $\nabla^{2} \mathrm{SST}$ is either positive or negative. In particular, at $t=15 \mathrm{~h}$, there is a strong asymmetry between regions of negative and positive SST Laplacian. The pdf is near Gaussian for $\nabla^{2} \mathrm{SST}>0$ with a significant negative mean. On the contrary, the pdf for $\nabla^{2} \mathrm{SST}<0$ shows a pronounced exponential tail for $w>0$. This indicates that more frequent strong ascents $\left(w>0.015 \mathrm{~ms}^{-1}\right)$ in localized regions due to negative SST Laplacian are compensated for by a mean slower descent in more extended regions $\left(w \approx-0.005 \mathrm{~ms}^{-1}\right)$ where SST Laplacian is positive. This behavior is less marked at $3 \mathrm{~h}$ (not shown). A second mechanism induced by boundary layer stability might be at work (as already found in the unidimensional case): positive SST anomalies (as often found when $-\nabla^{2}$ SST $>0$ ) induce a stronger destabilization of the MABL compared to negative SST anomalies, thus enhancing dry convection which reinforces the primary response to LN87 mechanism in these regions. On the contrary, negative SST anomalies will lead to divergence and will inhibit the response in these regions.

[23] The agreement between $w$ and $-\nabla^{2}$ SST can be quantified by computing their spatial correlation. This index is given as a function of time $t$ and altitude $z$ (at which $w$ is evaluated) in Figure $4 a$ with the time evolution of the maximum and the spatial mean height of the PBL. It indicates that high correlations (larger that 0.8 ) are found inside the boundary layer until $t=8 \mathrm{~h}$ and are still larger than 0.6 at $15 \mathrm{~h}$. In the first hours, significant correlations (larger than 0.4) are also found in the free troposphere above the PBL. This presumably results from gravity waves produced by the initial adjustment to the imposed SST. We also note that the spatial correlation slowly decreases over time, essentially because advection by the background jet is zonally shifting the $w$ structures (Figure 2e). Such a zonal shifting due to the presence of a zonal shear was also observed by Small et al. [2003, 2005] in regions of oceanic tropical instability waves and in the equatorial eastern Pacific.

[24] A spectral analysis is undertaken to highlight the range of spatial scales for which the atmosphere responds to the Laplacian of the SST. Isotropic vertical kinetic energy spectra at $t=3 \mathrm{~h}$ (dashed) and $t=15 \mathrm{~h}$ (dash-dotted) are compared in Figure 5a to the normalized spectrum of $-\nabla^{2} \mathrm{SST}$ (plain). (Note that the average meridional linear trend needs to be removed from the vertical velocity field $w$ in order to filter its short-time direct response to the heat flux, approximately proportional to the background meridional SST gradient.) First, we observe that the kinetic energy spectra do not evolve very much in time, even if the vertical velocity increases. The spectrum of the SST Laplacian is quite flat which is consistent with the $k^{-4}$ power law for the SST spectrum. A good agreement between the SST Laplacian and the vertical kinetic energy spectra can be observed for wave numbers smaller than $k_{\star} \approx 1.5 \times 10^{-4} \mathrm{~m}^{-1}$ (corresponding to a wavelength $\lambda_{\star}=42 \mathrm{~km}$ ). For the range of scales $k>k_{\star}$, the vertical kinetic energy spectrum is steeper than the spectrum of the SST Laplacian. This suggests that the atmospheric response to the SST could consist in a lowpass filter in space. At the smaller scales $\left(k>6 \times 10^{-4} \mathrm{~m}^{-1}\right)$, the kinetic energy spectrum falls down rapidly.

[25] To see what affects most the correlation between $w$ and $-\nabla^{2} \mathrm{SST}$, we also examine at $t=15 \mathrm{~h}$ the spectra of the Laplacians of potential temperature inside the PBL and of the surface heat flux (Figure 5b). As can be seen, the vertical velocity spectrum matches quite well with the one of the Laplacian of the temperature in the PBL up to $k=7 \times 10^{-4} \mathrm{~m}^{-1}$ (around $10 \mathrm{~km}$ ). This result suggests that it is the Laplacian of temperature of the PBL that sets the 
(a)

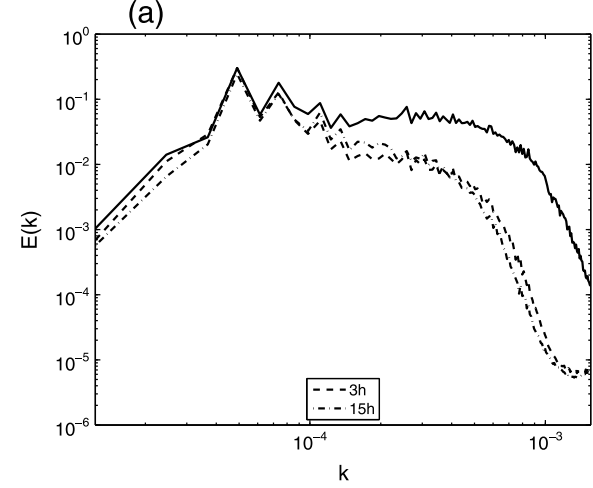

(b)

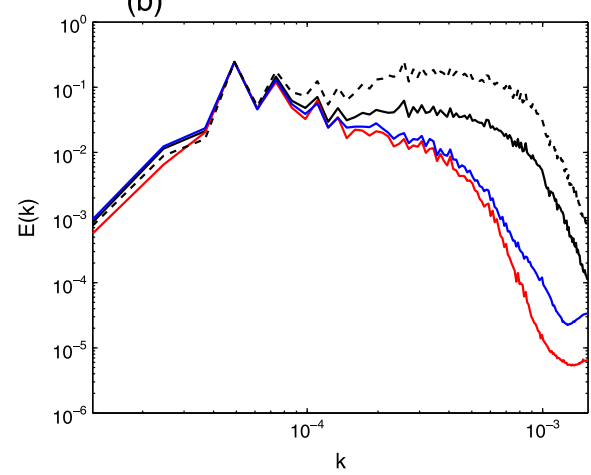

Figure 5. (a) Isotropic energy spectra of the vertical velocity $w$ for $t=3 \mathrm{~h}$ (dashed) and $t=15 \mathrm{~h}$ (dash-dotted). They are compared to the normalized spectrum of $-\nabla^{2} \mathrm{SST}$ (plain). (b) Isotropic spectra of Laplacian of temperature at the center of the PBL (blue), $w$ at the center of the PBL (red), Laplacian of SST (continuous black curve), Laplacian of surface heat flux (dashed black curve) at $t=15 \mathrm{~h}$. Wavenumber $k$ in $\mathrm{m}^{-1}$.

vertical velocity. The lack of correlation between $-\nabla^{2}$ SST and $w$ above $k>k_{\star}$ is therefore due to the lack of correlation between SST and temperature in the PBL for those scales. Note that the normalization of the $\nabla^{2}$ SST spectrum is chosen by assuming a good correspondence with the vertical kinetic energy spectrum for the first wave numbers. Consequently, the value $k_{\star}$ could not be significant. On the other hand, the surface heat flux Laplacian does not possess any resemblance with $w$ at high wave numbers.
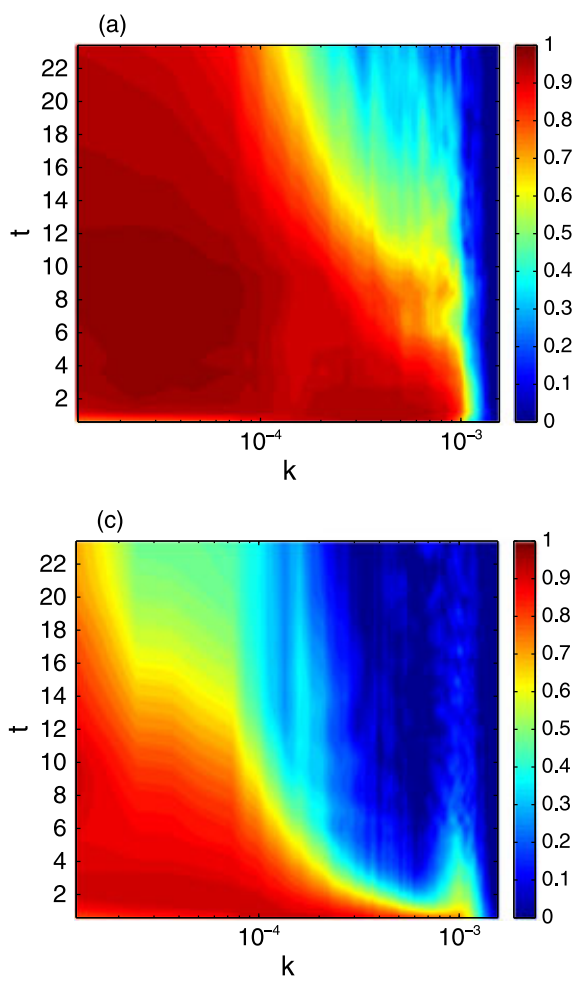

[26] In order to complete this analysis, a spectral correlation is performed between the concerned fields. To do this, for each wave number $k$, we band-pass filter $w$ and $-\nabla^{2}$ SST between $k-\delta k / 2$ and $k+\delta k / 2$ with $\delta k=10^{-4} \mathrm{~m}^{-1}$. Then we compute the correlation of the filtered field in the spatial space (sensitivity tests done varying $\delta k$ do not show qualitative change in the results). Figure 6a shows the spectral correlation as a function of time at the center of the PBL height. For the early times $(t<5 \mathrm{~h})$, we observe a relatively
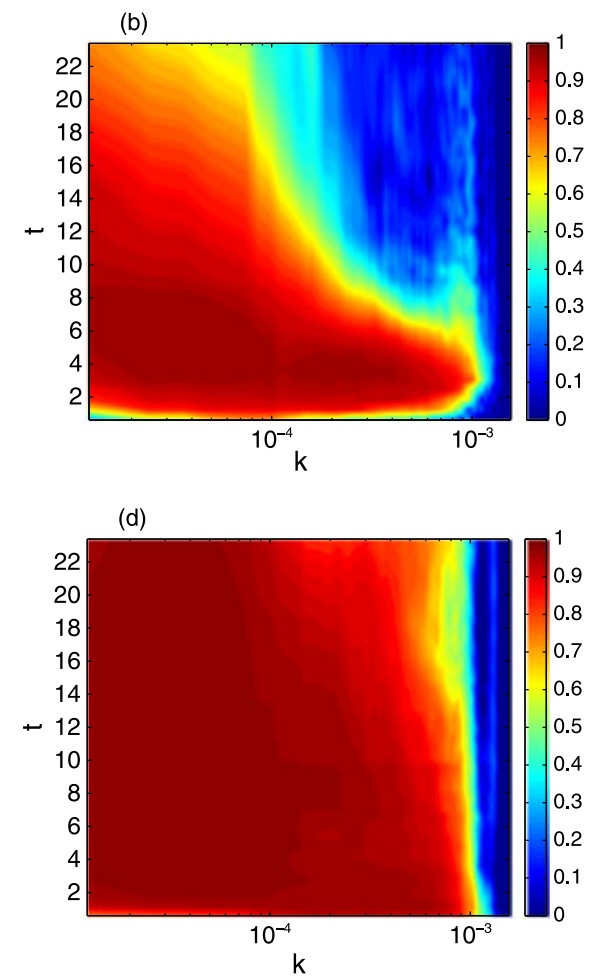

Figure 6. Spectral correlation between $-\nabla^{2}$ SST and the vertical velocity $w$ at the center of the PBL height, as a function of time (in $\mathrm{h}$ ) and wavenumber (in $\mathrm{m}^{-1}$ ) for (a) the reference case, (b) a doubled vertical shear $\left(U_{H}=20 \mathrm{~ms}^{-1}\right)$ (c) with an additional uniform wind $\left(U_{0}=1 \mathrm{~ms}^{-1}\right)$. (d) Spectral correlation between the Laplacian of the temperature and the vertical velocity $w$ both taken at the middle of the PBL for the reference case. 


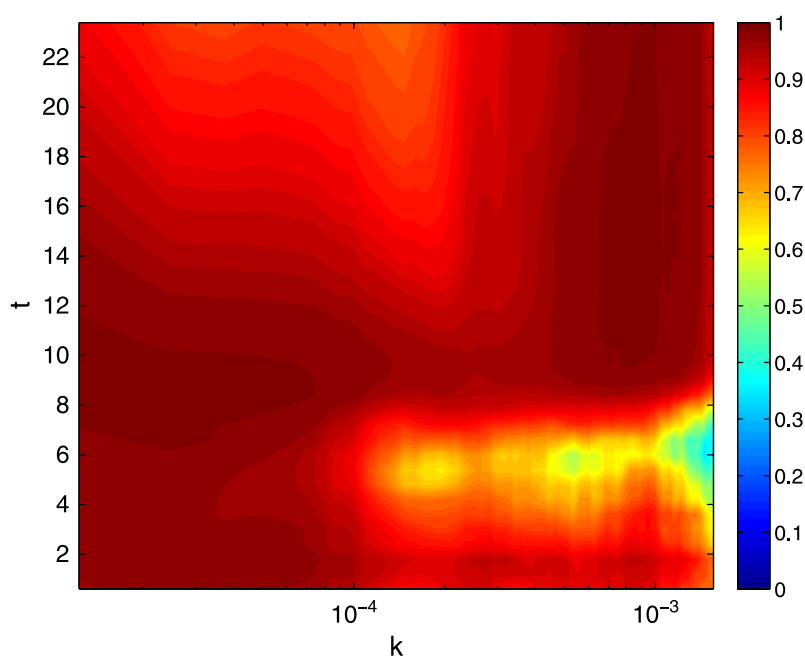

Figure 7. Spectral correlation between the Laplacians of SST and the surface heat flux as a function of time (in h) and wavenumber $\left(\right.$ in $\mathrm{m}^{-1}$ ) for the reference case.

high correlation $(>0.80)$ at all scales below $10^{-3} \mathrm{~m}^{-1}$. This correlation gradually decreases over time but its decrease rate is more rapid for smaller scales, so that high values of correlation can still be observed for small wave numbers even for long times $(t=20 \mathrm{~h})$.

[27] This result can be compared with Figure 6d showing the spectral correlation for the Laplacian of the temperature inside the PBL. High values are found at all scales (except for $k>10^{-3} \mathrm{~m}^{-1}$ ), but unlike Figure $6 \mathrm{a}$, they persists for longer times. This confirms that the lack of correlation here is mostly related to the adjustment of the temperature in the PBL to the SST (see Figure 5b).

[28] This adjustment between SST and PBL temperature is forced by the surface heat fluxes (directly related to the difference between SST and the temperature at the base of the PBL). But this adjustment is also affected by the horizontal advection of the PBL temperature. This is illustrated by the comparison of Figure 7 and Figures 6 a and $6 \mathrm{~d}$. Figure 7 shows the time evolution of the spectral correlation between the Laplacians of SST and surface heat flux. As expected, this correlation is good at all scales. There is only a slight decrease of the correlation for small scales between $t=4 \mathrm{~h}$ and $t=6 \mathrm{~h}$. On the other hand, the spectral correlation between the Laplacians of PBL temperature and SST (not shown, but it can be deduced from Figures $6 a$ and 6d) significantly decreases for a scale range involving first the smallest scales and larger scales for longer times. This emphasizes the impact of horizontal advection terms, as time goes on, on the PBL temperature. These advection terms in the temperature equation tend to homogenize the PBL temperature at small scales [Spall, 2007]. Since $w$ is strongly correlated with the PBL temperature, this illustrates the role of low-pass filter played by the advection terms for the LN87 mechanism.

[29] Finally, the assumptions and framework of LN87 provide a linear relationship between $w$ and the SST Laplacian and we can try to evaluate the proportionality coefficient. Using Ekman layer theory, Feliks et al. [2004] have computed the coefficient of proportionally relating $w$ to the
Laplacian of the SST. They found a coefficient such that $w=-\alpha_{\text {theo }} \nabla^{2}$ SST with

$$
\alpha_{\text {theo }}=\frac{g H_{e}^{2}}{f_{0} \theta_{0}} \frac{1}{2 \pi}\left(1-\frac{1}{2 \pi}\right),
$$

where $g$ is the gravitational acceleration, $H_{e}$ the height of the Ekman layer considered by the authors as the PBL height, $f_{0}$ the Coriolis parameter, and $\theta_{0}$ the reference potential temperature. We now compare the theoretical value of the coefficient of proportionality and an estimation from the simulation by the following ratio

$$
\alpha_{\text {est }}(\mathrm{SST})=-\frac{\left\langle w \nabla^{2} \mathrm{SST}\right\rangle}{\left\langle\left(\nabla^{2} \mathrm{SST}\right)^{2}\right\rangle},
$$

where $\langle\cdot\rangle$ denotes the horizontal average. The coefficients $\alpha_{\text {est }}(\mathrm{SST})$ and $\alpha_{\text {theo }}$ are respectively $4.7 \times 10^{6} \mathrm{~m}^{3} \mathrm{~s}^{-1} \mathrm{~K}^{-1}$ and $11 \times 10^{6} \mathrm{~m}^{3} \mathrm{~s}^{-1} \mathrm{~K}^{-1}$ for $t=15 \mathrm{~h}$ where $H_{e}$ is here considered as the center of the mean PBL and $\theta_{0}=280 \mathrm{~K}$ (see Table 1 ).

[30] The estimated coefficient is significantly smaller than the theoretical one, even if we see that the value proposed by Feliks et al. [2004] almost gives the right order of magnitude. The difference could partly come from the assumption that the PBL temperature adjusts to the SST which fails for the smaller scales at this time (see Figures $6 \mathrm{a}$ and 6d). By estimating this coefficient using the Laplacian of the temperature inside the PBL, a value a little closer to the theoretical one is found: $\alpha_{\text {est }}(\theta)=17 \times 10^{6} \mathrm{~m}^{3} \mathrm{~s}^{-1} \mathrm{~K}^{-1}$.

[31] The relation between the vertical velocity and the Laplacian of SST is thus well verified, both qualitatively and quantitatively, mainly during the early times of this idealized case. In the next sections, its robustness is tested by modifying different parameters of the present configuration.

\section{Sensitivity to the Spatial Scales in SST}

[32] The SST perturbation field $f(x, y)$ used in the above numerical experiment presents an energy spectrum following a $k^{-4}$ power law, whereas SST spectra in the real ocean rather follow a $k^{-2}$ power law [Klein et al., 2008]. The reference case of section 4 here is compared to an alternative case in the same configuration but with another SST perturbation field $g(x, y)$ for which the energy spectrum follows a $k^{-2.5}$ power law closer to the reality. Such a SST perturbation is constructed by taking an instantaneous snapshot of a numerical simulation of surface quasigeostrophic turbulence

Table 1. Values of Different Parameters at $t=15 \mathrm{~h}$ for the Different Cases

\begin{tabular}{lccccc}
\hline Case & Ref & $2 \times U$ & $U+U_{0}$ & MYNN & $k^{-2.5} \mathrm{SST}$ \\
\hline$<h_{\mathrm{PBL}}>(m)$ & 971 & 993 & 1097 & 678 & 975 \\
$\mathrm{SST}_{\mathrm{RMS}}\left(10^{-2} \mathrm{~K}\right)$ & 13 & 13 & 13 & 13 & 8.2 \\
$\theta_{\mathrm{RMS}}\left(10^{-2} \mathrm{~K}\right)$ & 8.5 & 8.7 & 7.6 & 4.3 & 4.5 \\
$\nabla^{2} \mathrm{SST}_{\mathrm{RMS}}\left(10^{-10} \mathrm{Km}^{-2}\right)$ & 8.2 & 8.2 & 8.2 & 8.2 & 33 \\
$\nabla^{2} \theta_{\mathrm{RMS}}\left(10^{-10} \mathrm{Km}^{-2}\right)$ & 3.4 & 3.1 & 2.4 & 2 & 8.4 \\
$<Q>\left(\mathrm{Wm}^{-2}\right)$ & 8.9 & 9.2 & 10 & 8.2 & 8.8 \\
$w_{\mathrm{RMS}}\left(10^{-3} \mathrm{~ms}^{-1}\right)$ & 5.7 & 5.7 & 5.3 & 0.9 & 13 \\
$\left\|\nu_{10}\right\|_{\mathrm{RMS}}\left(10^{-2} \mathrm{~ms}^{-1}\right)$ & 3.3 & 5.4 & 16 & 3 & 13 \\
$\alpha_{\text {est }}(\mathrm{SST})\left(10^{6} \mathrm{~m}^{3} \mathrm{~s}^{-1} \mathrm{~K}^{-1}\right)$ & 4.7 & 3.3 & 2 & 0.84 & 2.1 \\
$\alpha_{\text {est }}(\theta)\left(10^{6} \mathrm{~m}^{3} \mathrm{~s}^{-1} \mathrm{~K}^{-1}\right)$ & 17 & 19 & 22 & 4.8 & 16 \\
$\alpha_{\text {theo }}\left(10^{6} \mathrm{~m}^{3} \mathrm{~s}^{-1} \mathrm{~K}^{-1}\right)$ & 11 & 12 & 14 & 5.4 & 11 \\
\hline
\end{tabular}


(a)

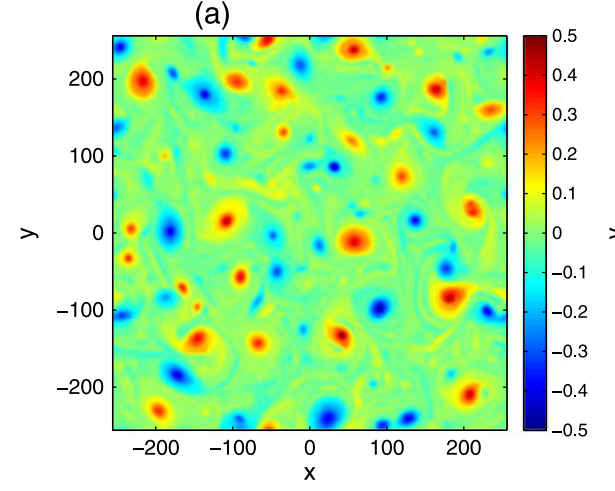

(c)

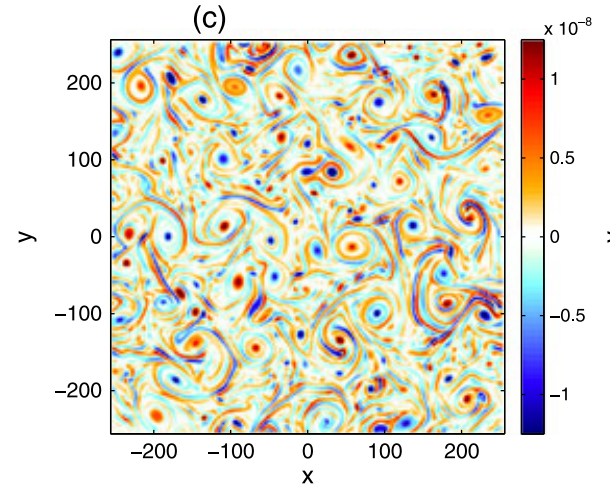

(b)

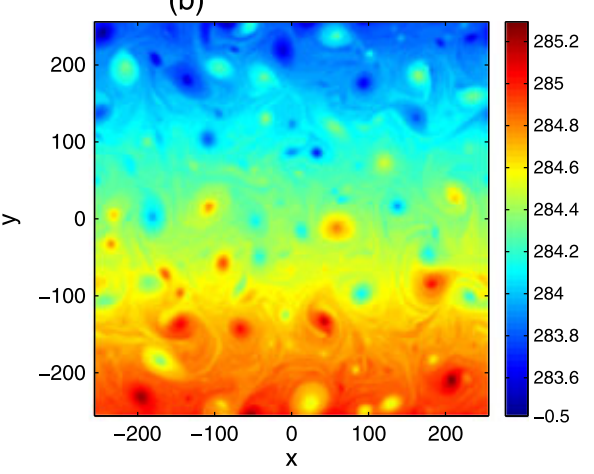

(d)

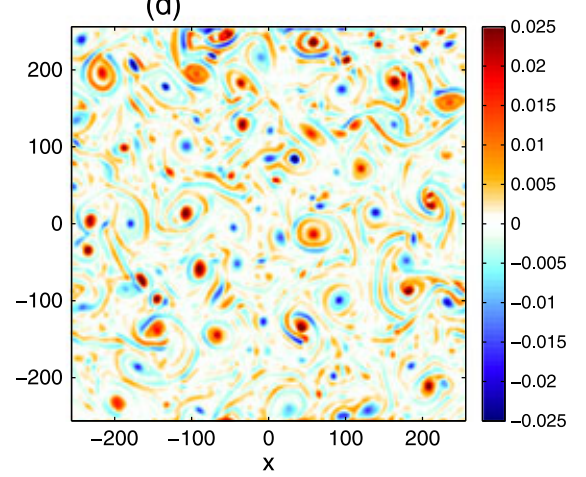

Figure 8. (a) SST perturbation field of the alternative SST case. (b) Total SST pattern (in K). (c) Minus Laplacian of the SST field (in $\mathrm{K} \mathrm{m}^{-2}$ ). (d) Vertical velocity field $w$ (in $\mathrm{m} \mathrm{s}^{-1}$ ) at the center of the mean PBL height at $t=3$ h. $x$ and $y$ in Kilometers.

[see for instance, Capet et al., 2008]. This new SST perturbation and its associated SST pattern are shown in Figures $8 \mathrm{a}$ and $8 \mathrm{~b}$, respectively. As the reference case, the perturbation field $g(x, y)$ comprises coherent structures but of smaller scales, as vortices of diameters of less than $50 \mathrm{~km}$. Comparing Figure $8 \mathrm{~b}$ with Figure $2 \mathrm{~b}$, the SST anomalies are strongly localized and less smooth in space and their rootmean-square (RMS) value is a little smaller than in the reference case (see Table 1). The SST Laplacian (Figure 8c) is dominated by eddies of about $30 \mathrm{~km}$ of diameter and submesoscale filaments.
[33] As in the reference case, a good spatial correlation is found between the Laplacian of the SST field and the atmospheric response in the vertical velocity field $w$ inside the PBL for the early hours (Figure 8). The spectral analysis of Figure 9a shows a satisfactory correspondence between the isotropic spectra of the two fields, at least for $k<k_{\star}=$ $1.5 \times 10^{-4} \mathrm{~m}^{-1}$. Above $k=k_{\star}$, the variance of $w$-field (red curve) starts to decrease as does the spectrum of the PBL temperature (blue curve), as was observed for the reference case (see Figure 5b). In contrast with the reference simulation, the spectrum of $w$ here has a stronger contribution (a)

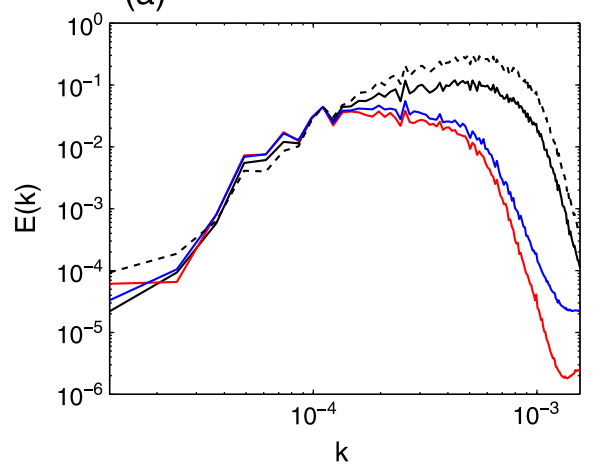

(b)

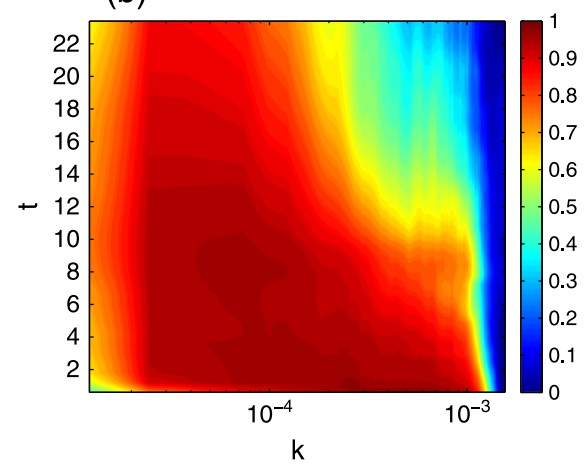

Figure 9. (a) Isotropic spectra of Laplacian of temperature at the center of the PBL (blue), $w$ at the center of the PBL (red), Laplacian of SST (continuous black curve), Laplacian of surface heat flux (dashed black curve) at $t=15 \mathrm{~h}$. (b) Spectral correlation between $-\nabla^{2} \mathrm{SST}$ and the vertical velocity $w$ (as in Figure 6) for the case described in section 5 . 
from submesoscales than from mesoscales, consistent with the Laplacian of the SST.

[34] The associated spectral correlation given in Figure 9b shows a good correlation $(>0.8)$ at all scales up to $10 \mathrm{~h}$ and then this correlation decreases faster for the small scales than the larger ones. This behavior is similar to the one of the reference case (see Figure 6a), except for the very first wave numbers $\left(k<2.5 \times 10^{-4} \mathrm{~m}^{-1}\right)$. This could be caused by the low SST variance contained in those scales compared to the reference case and the persistence of a direct nonlinear response of the vertical velocity to the surface heat flux at those scales. Again, the progressive lack of correlation (more intense as the scale is small) is mostly due to the adjustment of the PBL temperature to the SST, as we found by computing the spectral correlation with the Laplacian of the PBL temperature (not shown). Note that the correlation values here are a bit weaker compared to the reference case even for the large scales $\left(k<k_{\star}\right)$. We also observe that, for the first hours, high correlation values $(>0.80)$ extend to a range of smaller scales (up to $k=1.4 \times 10^{-4} \mathrm{~m}^{-1}$ instead of $k=1.0 \times 10^{-4} \mathrm{~m}^{-1}$ for the reference case) likely due to the use of a finer pattern of the SST Laplacian.

[35] One important difference with the reference case is that the vertical velocity RMS $w_{\mathrm{RMS}}$ is twice larger although $S S T_{\mathrm{RMS}}$ is a little smaller (see Table 1). This result strongly emphasizes the high impact of submesoscales on vertical velocities, as inferred from the LN87 mechanism. Actually, because of the presence of submesoscales, the RMS value of the Laplacian of SST is four times larger and that for the temperature within the boundary layer is twice larger.

[36] Finally, in this new experiment, the estimated value of the coefficient of proportionality $\alpha_{\text {est }}(\mathrm{SST})$ (see equation (7)) between $w$ and $-\nabla^{2} \mathrm{SST}$ is almost of the same order of magnitude $\left(10^{6} \mathrm{~m}^{3} / \mathrm{K} / \mathrm{s}\right)$ as the theoretical one $\alpha_{\text {theo }}$ (see equation (6)) for $t=15 \mathrm{~h}$ (see Table 1). And again, a better correspondence is found with the theoretical value by using the Laplacian of the PBL temperature: $\alpha_{\text {est }}(\theta)$. Note that the theoretical value here is identical to the one of the reference case since the PBL reaches the same height in both cases (see Table 1).

\section{Sensitivity Analyses}

[37] To see if our results are valid for different situations, we propose to make different sensitivity tests on the reference case.

[38] We have tested the sensitivity of the results to the PBL parameterization. For that purpose, we have used the Mellor-Yamada-Nakanishi-Niino (MYNN) 2.5 level scheme. This scheme is a turbulent kinetic energy based local mixing scheme [Nakanishi and Niino, 2006] where TKE is generated by the local shear instability. Thus, it differs from the YSU PBL scheme that employs countergradient terms to represent fluxes due to nonlocal gradients, a physical process that is important for the convection-driven situations. For consistency, a MYNN surface layer scheme is used with the Mellor-Yamada PBL scheme. The vertical velocity field $w$ at the center of the PBL at $t=3 \mathrm{~h}$ is shown in Figure 2f. Compared to the reference case (see Figure 2d), it also closely resembles the Laplacian of SST (see Figure 2c) but with a noisier pattern which is presumably caused by the local feature of the MYNN scheme. Even if it is a little longer to settle (after $t=2 \mathrm{~h}$ ), a significant spatial correlation is found between the two fields inside the PBL for the first $24 \mathrm{~h}$, as seen in Figure 4b. This scheme thus reproduces similar results as the YSU scheme. Spectral correlations show qualitatively the same results (not shown). Nevertheless, it provides a less active PBL compared to the reference case (see Table 1): the amplitude of the vertical velocity field is of one order of magnitude weaker $\left(9 \times 10^{-4} \mathrm{~ms}^{-1}\right.$ instead of $\left.5.7 \times 10^{-3} \mathrm{~ms}^{-1}\right)$ and the mean PBL reaches a lower altitude $\sim 680 \mathrm{~m}$ instead of $\sim 970 \mathrm{~m}$ at $t=15 \mathrm{~h}$. One explanation for the weak $w$ amplitudes is that the MYNN scheme was developed for situations of neutral turbulence, whereas the situation considered in this study is driven by convection, for which the YSU PBL scheme is much more appropriate.

[39] We also examined the dependence on the shear of the background zonal jet by doubling $U_{H}$ in equation (4) $\left(U_{H}=20 \mathrm{~ms}^{-1}\right)$, in order to measure the effect of the advection on the previous results. We still observe a good correlation between vertical velocity in the PBL and the SST Laplacian (Figure 4c). The advection limits the correlation which decreases more rapidly over time, e.g., reaching 0.5 at $t=5 \mathrm{~h}$. The same behavior is observed for the spectral correlation in Figure 6b. During the first few hours, a direct response of $w$ to the surface sensible heating with a mean meridional gradient is observed (not shown). This response is overcome by the response to $\nabla^{2} \mathrm{SST}$ after $2 \mathrm{~h}$. The stronger advection restricts the correlation in time at all scales. A simple scaling argument can explain the timescale for the decorrelation between $w$ and $\nabla^{2}$ SST. Using a horizontal length scale $L=20 \mathrm{~km}$ (half the wavelength corresponding to $\left.k_{\star}\right)$ and an estimation of the velocity at the middle of the $\operatorname{PBL}\left(U_{\mathrm{adv}}=U_{H} h /\left(2 H_{\mathrm{top}}\right)\right.$, where $h$ is the height of the PBL and $U_{H}$ and $H_{\text {top }}$ the parameters of equation (4)), the time of decorrelation between the atmospheric temperature (first equal to SST and then advected by the zonal wind) and the SST field is $T_{\mathrm{adv}}=L / U_{\mathrm{adv}}$. For $U_{H}=20 \mathrm{~ms}^{-1}$, this gives $T_{\mathrm{adv}} \approx 7 \mathrm{~h}$ which is consistent with Figures $4 \mathrm{c}$ and $6 \mathrm{~b}$. For $U_{H}=10 \mathrm{~ms}^{-1}$, this would give $T_{\mathrm{adv}} \approx 13 \mathrm{~h}$ which is also consistent with Figures $4 \mathrm{a}$ and $6 \mathrm{a}$.

[40] In all the above simulations, the surface winds are initially set to zero, limiting the effects of advection in the PBL. Hence, another test of the sensitivity to the background wind profile consists in adding a uniform wind $U_{0}=1 \mathrm{~ms}^{-1}$ all over the vertical domain: $U(z)=U_{0}+\left(U_{H} z / H_{\text {top }}\right)$ where $U_{H}=$ $10 \mathrm{~ms}^{-1}$. In this case, as expected, the spatial and spectral correlation are both weakened and rapidly decrease under the effects of advection, see Figures $4 \mathrm{~d}$ and $6 \mathrm{c}$. Using the same reasoning as above, we have $U_{\text {adv }}=U_{0}+\left(U_{H} h / H_{\text {top }}\right)$, which gives $T_{\mathrm{adv}} \approx 4 \mathrm{~h}$ in good agreement with what we observe. These results show how sensitive the amplitude of the atmospheric response is to the intensity of the background surface wind.

[41] The cause is simply the shift between the anomalies of SST and the advected PBL temperature, which decreases the efficiency of the LN87 mechanism. The effect of advection is stronger at smaller scales, making the PBL temperature at small scales less correlated to the SST field. This is confirmed by the moderate decrease of the RMS of the Laplacian of the PBL temperature with respect to the reference case's value (see Table 1 ).

[42] As before, the coefficient of proportionality relating $w$ to the Laplacian of the SST has been estimated at 
$t=15 \mathrm{~h}$ for each sensitivity test presented in this section (see Table 1). We still observe a comparable order of magnitude between the estimated values (equation (7)) and the theoretical ones (equation (6)) but with a better fit for the estimation using the Laplacian of the PBL temperature.

\section{Discussion}

[43] This study has shown the relevance of the mechanism provided by Lindzen and Nigam [1987] and revisited by Feliks et al. [2004] to describe the atmospheric response to a SST pattern, in the midlatitudes, when appropriate conditions (weak winds) are encountered. More precisely, for a SST eddy field involving both mesoscales and submesoscales, quantitative analysis both in spatial and (horizontal) spectral spaces show that there exists a quasi-linear relation between the vertical velocity of the atmospheric boundary layer and the SST Laplacian. This was proven in different simulations (with different SST patterns, largescale atmospheric states, or PBL parameterizations) performed with the WRF model in an idealized configuration. Note that these results do not depend on the horizontal and vertical resolution: simulations with double $(1 \mathrm{~km})$ horizontal resolution or with stretched or not stretched vertical levels give the same results both quantitatively and qualitatively.

[44] In all simulations, a significant spatial correlation between the SST Laplacian and the vertical velocity is observed within the entire PBL as long as the advective time scale is not reached. A nonlinear component is also found in the response such that ascents in positive SST anomalies are generally much stronger than descents in negative SST anomalies. The role of low-pass filter played by the advection in the adjustment of PBL temperature to the SST has been highlighted to explain the decrease of correlation between $w$ and $-\nabla^{2}$ SST at smaller scales. Moreover, tests performed with stronger vertical wind shear or stronger surface wind show how sensitive the atmospheric response is to advection. The transition to other mechanisms for the atmospheric response when the surface winds are stronger will require further investigations.

[45] The present investigation is a first step in exploring the atmospheric response to mesoscale and submesoscale SST anomalies. It establishes the importance of the LN87 mechanism at scales that were hitherto rather unexplored, yet it restricts to wind conditions that are favorable. Investigating the atmospheric response in strong wind condition and the effects due to moisture calls for further investigations.

[46] The atmospheric response that we observe $w \propto$ $-\nabla^{2} \mathrm{SST}$ is different from what has been obtained by other studies [O'Neill et al., 2003; Xie, 2004]. O'Neill et al. [2003] observed the horizontal divergence of the wind stress $\nabla \cdot \tau$ to be proportional to $(\tau /|\tau|) \cdot \nabla \mathrm{SST}$ corresponding to the mechanism of downward momentum mixing [Wallace et al., 1989]. Moreover, Xie [2004] observed the surface wind speed to be proportional to the SST anomalies. We have examined both relationships in our simulations and neither of them were observed. Indeed, we observed that the surface wind speed is proportional to the SST gradients $|\boldsymbol{v}| \propto|\nabla \mathrm{SST}|$ (not shown). Such a relation can be easily deduced from equation (1). For a regime with moderate to high winds, two causes should limit the LN87 response and may promote the observations of Xie [2004] and O'Neill et al. [2003]: first, the temperature will be advected horizontally, so that it will not be able to adjust to SST through the local surface heat flux. This has been observed by Small et al. [2003, 2005] in the Pacific tropical regions. These authors showed that pressure and temperature anomalies in the PBL were shifted from the SST anomalies in the direction of the wind. Second, downward momentum mixing should intensify and be more dominant than the pressure gradient in the momentum equation.

[47] Regarding moisture, moist convection will be enhanced over warm SST anomalies and inhibited over cold anomalies. This suggest a response where $w_{\text {moist }}$ is of the same sign as the SST anomalies, which for mesoscale eddies should be of the same sign as the LN87 mechanism $\left(w_{\text {LN87 }} \propto-\nabla^{2} \mathrm{SST}\right)$. Hence, it should amplify the correlation and the amplitude of the atmospheric response.

[48] More strikingly, this study has emphasized the strong impact of the SST submesoscales on the atmospheric response via the LN87 mechanism by using patterns presenting both mesoscales (eddies) and submesoscales (filaments), contrary to past studies that only examined a large-scale front such as the Gulf Stream [e.g., Brachet et al., 2012]. The results remarkably show that using a SST pattern with a similar SST RMS value but with finer scales extends the range of smaller scales in the atmospheric response and significantly increases its intensity. Consequently, it is essential for coupled global climate models to resolve oceanic submesoscales as these scales strongly contribute to the vertical velocities in the mixed layer.

[49] It will be interesting to examine how the atmospheric convergence/divergence patterns triggered by the presence of oceanic fronts at mesoscale and submesoscale can in turn statistically intensify or damp these fronts. Indeed, the atmospheric circulation induced by a SST front does in turn drive an Ekman flow that may intensify or damp this SST front. As shown by Thomas and Lee [2005], these intensification and damping effects strongly depend on the characteristics of the SST front relative to the wind amplitude and direction. When considering an ocean turbulent eddy field, as in the present study, characteristics of SST fronts cover a large-spectrum range. This may lead to a positive or negative statistical feedback of the atmosphere on these SST fronts. But only a coupled atmosphere ocean model will allow to estimate the sign and amplitude of this feedback. This should be addressed in a future study.

[50] Acknowledgments. We acknowledge financial support from Agence Nationale de la Recherche under the reference ANR 2011 Blanc SIMI 5-6 01401 . This work was granted access to the HPC resources of [CCRT/CINES/IDRIS] under the allocation 2011-016852 made by GENCI (Grand Equipement National de Calcul Intensif). We acknowledge Lionel Guez in helping to set up the WRF simulations.

\section{References}

Bourras, D., G. Reverdin, H. Giordani, and G. Caniaux (2004), Response of the atmospheric boundary layer to a mesoscale oceanic eddy in the northeast atlantic, J. Geophys. Res., 109, D18114, doi:10.1029/2004JD004799.

Brachet, S., F. Codron, Y. Feliks, M. Ghil, H. LeTreut, and E. Simmonet (2012), Atmospheric circulations induced by a midlatitude SST front: A GCM study, J. Climate, 25, 1847-1853.

Businger, J. A., and W. J. Shaw (1984), The response of the marine boundary layer to mesoscale variations in sea-surface temperature, Dyn. Atmos. Oceans, 8, 267-281. 


\section{LAMBAERTS ET AL.: ATMOSPHERIC RESPONSE TO SST MESOSCALES}

Capet, X., P. Klein, B. L. Hua, G. Lapeyre, and J. C. McWilliams (2008), Surface kinetic and potential energy transfer in SQG dynamics, J. Fluid Mech., 604, 165-174.

Chelton, D. B., M. G. Schlax, M. H. Freilich, and R. F. Millif (2004), Satellite measurements reveal persistent small-scale structures in ocean winds, Science, 303, 978 .

De Monte, S., C. Cotté, F. d'Ovidio, M. Lévy, M. Le Corre, and H. Weimerskirch (2013), Frigatebird behaviour at the ocean-atmosphere interface: Integrating animal behaviour with multi-satellite data, J. Roy. Soc. Interface, 9, 3351-3358, doi:10.1098/rsif.2012.0509.

Deremble, B., G. Lapeyre, and M. Ghil (2012), Atmospheric dynamics triggered by an oceanic SST front in a moist quasi-geostrophic model, $J$. Atmos. Sci., 69, 1617-1632.

Doyle, J. D., and T. T. Warner (1990), Mesoscale coastal processes during GALE IOP2, Mon. Weather Rev., 118, 283-308.

Feliks, Y., M. Ghil, and E. Simonnet (2004), Low-frequency variability in the midlatitude atmosphere induced by an oceanic thermal front, $J$. Atmos. Sci., 61, 961-981.

Feliks, Y., M. Ghil, and E. Simonnet (2007), Low-frequency variability in the midlatitude baroclinic atmosphere induced by an oceanic thermal front, J. Atmos. Sci., 64, 97.

Giordani, H., and S. Planton (2000), Modeling and analysis of ageostrophic circulation over the azores oceanic front during the SEMAPHORE experiment, Mon. Weather Rev., 128, 2270-2287.

Hong, S.-Y., Y. Noh, and J. Dudhia (2006), A new vertical diffusion package with explicit treatment of entrainment processes, Mon. Weather Rev., 134, 2318-2341.

Klein, P., B. L. Hua, G. Lapeyre, X. Capet, S. L. Gentil, and H. Sasaki (2008), Upper ocean turbulence from high 3-D resolution simulations, $J$. Phys. Oceanogr., 38, 1748-1763.

Knievel, J., G. Bryan, and J. Hacker (2007), Explicit numerical diffusion in the WRF model, Mon. Weather Rev., 135, 3808-3824.

Lindzen, R. S., and S. Nigam (1987), On the role of sea surface temperature gradients in forcing low level winds and convergence in the tropics, $J$. Atmos. Sci., 44, 2418-2436.

Minobe, S., A. Kuwano-Yoshida, N. Komori, S.-P. Xie, and R. Small (2008), Influence of the Gulf Stream on the troposphere, Nature, 452, 206-209.

Nakamura, H., T. Sampe, A. Goto, W. Ohfuchi, and S.-P. Xie (2008), On the importance of midlatitude oceanic frontal zones for the mean state and dominant variability in the tropospheric circulation, Geophys. Res. Lett., 35, L15709, doi:10.1029/2008GL034010.

Nakamura, H., T. Sampe, T. S. Y. Tanimoto, and A. Shimpo (2004), Observed associations among storm tracks, jet streams, and midlatitude oceanic fronts, in Earth's Climate: The Ocean-Atmosphere Interaction, vol. 147, edited by C. Wang, S.-P. Xie, and A. Carton, pp. 329-345, AGU, Washington, D. C.

Nakanishi, M., and H. Niino (2006), An improved Mellor-Yamada level-3 model: Its numerical stability and application to a regional prediction of advection fog, Bound. Layer Meteor., 119, 397-407.

O'Neill, L. W., D. B. Chelton, and S. K. Esbensen (2003), Observations of SST-induced perturbations of the wind stress field over the southern ocean on seasonal timescales, J. Climate, 16, 2340-2354.

Plougonven, R., and V. Zeitlin (2009), Nonlinear development of inertial instability in a barotropic shear, Phys. Fluids, 21, 106601, doi:10.1063/1.3242283.

Shuckburgh, E., G. Maze, D. Ferreira, J. Marshall, H. Jones, and C. Hill (2011), Mixed layer lateral eddy fluxes mediated by air-sea interaction, J. Phys. Oceanogr, 41, 130-144.

Skamarock, W. C., J. B. Klemp, J. Dudhia, D. O. Gill, D. M. Barker, M. Duda, X.-Y. Huang, W. Wang, and J. G. Powers, (2008), A description of the advanced research WRF version 3, Tech. Rep., National Center for Atmospheric Research (NCAR) Technical Note, Boulder, Colorado, USA.

Small, R., S. deSzoeke, S. Xie, L. O’Neill, H. Seo, Q. Song, P. Cornillon, M. Spall, and S. Minobe (2008), Air-sea interactions over ocean fronts and eddies, Dyn. Atmos. Oceans, 45, 274-319.

Small, R., S.-P. Xie, and Y. Wang (2003), Numerical simulation of atmospheric response to tropical instability waves, J. Climate, 16, 3723-3741.

Small, R., S.-P. Xie, Y. Wang, S. Esbensen, and D. Vickers (2005), Numerical simulation of boundary layer structure and cross-equatorial flow in the eastern Pacific, J. Atmos. Sci., 62, 1812-1830.

Spall, M. A. (2007), Midlatitude wind stress-sea surface temperature coupling in the vicinity of oceanic fronts, J. Climate, 20, 3785-3801.

Takamata, K., S. Minobe, M. Inatsu, and R. Small (2012), Diagnostics for near-surface wind convergence/divergence response to the Gulf Stream in a regional atmospheric model, Atmos. Sci. Lett., 13, 16-21.

Thomas, L., and C. Lee (2005), Intensification of ocean fronts by downfront winds, J. Phys. Oceanogr., 35, 1086-1102.

Wai, M. M.-K., and S. A. Stage (1989), Dynamical analysis of marine atmospheric boundary layer structure near the Gulf Stream oceanic front, $Q$. J. R. Meteorol. Soc., 115, 29-44.

Wallace, J., T. Mitchell, and C. Deser (1989), The influence of sea-surface temperature on surface wind in the eastern equatorial Pacific: Seasonal and interannual variability, J. Climate, 2, 1492-1499.

Xie, S.-P. (2004), Satellite observations of cool ocean-atmosphere interaction, Bull. Amer. Meteor. Soc., 85, 195-208. 